\title{
EOQ Model for Constant Demand Rate with Completely Backlogged and Shortages
}

\author{
R. P. Tripathi* and Neha Sang \\ Department of Mathematics, Graphic Era University, Dehradun, Uttarakhand, India
}

\begin{abstract}
This paper presents an EOQ model with constant demand rate for non deteriorating items where shortages are allowed. In this paper shortages are considered as completely backlogged. The production rate is assumed to be proportional to demand rate and finite. The optimal solution of the model has been done for finding optimal time, optimal average cost by considering four different situations. Numerical example and sensitivity analysis is given to illustrate the proposed model.
\end{abstract}

Keywords: Demand; Inventory; Shortage; Production; Economic order quantity

\section{Introduction}

In last few decades, Mathematical ideas have been developed in different areas in real life problems, particularly for controlling inventory. The most important concern of the management is to decide when and how much to order so that the total cost connected with the inventory system should be minimum. This paper deals with the problems of determining EOQ model for non deteriorating items and constant demand rate. A number of authors have discussed inventory models for non-deteriorating items.

However, there are certain substances in which deterioration plays an important role and items cannot be stored for a long time. When items are kept in stock as an inventory for fulfilling the future demand, there may be deterioration of items in the inventory system, In inventory models generally four types of demand are assumed: (a) constant demand (b) time-dependent demand (c) probabilistic demand and (d) stock-dependent demand, inventory models dealing with constant demand have more relevance and common in the present situations.

Initially, the demand rate of items was considered to be constant. However, in real life situations, demand varies with time and situations. Goyal [1], developed an economic order quantity under conditions of permissible delay in payments. In paper [1] Goyal considered that the demand rate is constant. Chung et al. [2], established the optimal inventory policies under permissible delay in payments depending on the order quantity and total minimum variable cost per unit of time is obtained. Mahata and Mahata [3], developed optimal retailer's ordering policies in the EOQ model for deteriorating items under trade credit financing in supply chain. In paper [3] minimum retailer's optimal ordering policies are obtained. Huang [4], modified the assumption that the retailers will adopt the trade credit policy to stimulate his/ her customer demand to develop the retailer's replenishment model. Huang [4], assumed that the inventory lend is depleted by customer's demand alone. This assumption is valid for non permissible or non deteriorating inventory items. The demand rate for a particular item is not always constant it vary with time. Tripathi [5], established an EOQ model with time dependent demand rate and time-dependent holding cost functions. Tripathi [6], also established an optimal policy for items having constant demand and constant deterioration rate with trade credit. In this paper [6] a model for a retailer to determine its optimal price and time is obtained. Tripathi and Kumar [7], developed credit financing in economic ordering policies of time-dependent deteriorating items. This paper [7] presented the economic ordering policies in the presence of trade credit using discounted cash flows (DCF) approach.

Furthermore, when the shortages occur, it is assumed that it is either completely backlogged or completely lost. But in real life some customers are willing to wait for backorder and others would turn to buy from other sellers. Uthaya and Geetha [8], developed a replenishment policy for non-instantaneous deteriorating inventory system with partial backlogging. This paper [8] investigated an instantaneous replenishment inventory model for the non-instantaneous deteriorating items under cost minimization. Tripathi and Mishra [9], established an inventory model with shortage, time-dependent demand rate and quantity dependent permissible delay in payment. Patra et al. [10], established an order level EOQ model for deteriorating items in a single warehouse system with price dependent demand in non-linear form. In this paper [10] demand rae is considered as a function of selling price and order level inventory model for deteriorating items with single warehouse is developed where shortages are taken into consideration and it is completely backlogged. An EOQ model for permissible items with power demand and partial backlogging was developed by Singh et al. [11]. In paper [11] backlogging rate is considered as variable and dependent on the waiting time for the next replenishment. Research such as Park [12], Hollier and Mark [13], and Wee [14] considered the constant partial backlogging rate during the shortage period in their inventory models. Akad [15], established an EOQ model allowing shortage and partial backlogging. The thime proportion partial backlogging rate was developed by Chang and Dye [16], Wang [17], Teng and Yang [18], Yang [19], Wu et al [20], Dye et al. [21] and so on.

\section{Assumption and Notation}

The following assumptions and notations are used to develop the

${ }^{*}$ Corresponding author: R. P. Tripathi, Department of Mathematics, Graphic Era University, Dehradun, Uttarakhand, India, E-mail: tripathi_rp0231@rediffmail.com

Received October 31, 2012; Accepted December 08, 2012; Published December 11,2012

Citation: Tripathi RP, Sang N (2012) EOQ Model for Constant Demand Rate with Completely Backlogged and Shortages. J Applied Computat Mathemat 1:121. doi:10.4172/2168-9679.1000121

Copyright: (c) 2012 Tripathi RP, et al. This is an open-access article distributed under the terms of the Creative Commons Attribution License, which permits unrestricted use, distribution, and reproduction in any medium, provided the original author and source are credited. 
Citation: Tripathi RP, Sang N (2012) EOQ Model for Constant Demand Rate with Completely Backlogged and Shortages. J Applied Computat Mathemat 1:121. doi:10.4172/2168-9679.1000121

Page 2 of 4

proposed model:

- Demand rate $\mathrm{R}(\mathrm{t})$ is constant. Let it be $\mathrm{D}$.

- Deterioration rate is zero.

- Production rate is $P(t)=\lambda_{0} R(t)$ where $\left(\lambda_{0}>1\right)$ a constant therefore $\mathrm{P}(\mathrm{t})>\mathrm{R}(\mathrm{t})$.

- Lead time is zero.

- Shortages are allowed and are completely backlogged.

In addition the following notations are being made throughout the paper:

$C_{1}$ Carrying cost per unit per unit time.

$\mathrm{C}_{2}$ Shortage cost per unit per unit time.

$C_{3}$ Setup cost per production run.

$C_{1}, C_{2}, C_{3}$ are all assumed to be known and fixed during production cycle.

'AC' the total average cost for a production cycle.

\section{Mathematical Formulation}

Inventory level $\mathrm{I}(\mathrm{t})$ is zero at time $\mathrm{t}=0$. The shortages starts at $\mathrm{t}-0$ and accumulates up to the level $\mathrm{A}$ at time $\mathrm{t}=\mathrm{T}_{1}$. The production starts at $\mathrm{t}=\mathrm{T}_{1}$ and backlog is cleared at $\mathrm{t}=\mathrm{T}_{2}$. The stock-level reaches at level $\mathrm{B}$ at $\mathrm{t}=\mathrm{T}_{3}$. The production stopped at level $\mathrm{t}=\mathrm{T}_{3}$. Thus the inventory level decreases gradually due to demand and becomes zero at $\mathrm{t}=\mathrm{T}_{4}$. The cycle completed and repeals itself. $\mathrm{I}(\mathrm{t})$ is the inventory level at any time $\mathrm{t}$ $\left(0 \leq t \leq T_{4}\right)$. The differential equations of states are given by

$$
\begin{aligned}
& \frac{d I(t)}{d t}=-R(t), 0 \leq t \leq T_{1} \\
& \frac{d I(t)}{d t}=K(t)-R(t), \quad T_{1} \leq t \leq T_{2} \\
& \frac{d I(t)}{d t}=K(t)-R(t), \quad T_{2} \leq t \leq T_{3} \\
& \frac{d I(t)}{d t}=-R(t), \quad T_{3} \leq t \leq T_{4}
\end{aligned}
$$

With boundary conditions

$$
I(0)=0, I\left(T_{1}\right)=-A, I\left(T_{2}\right)=0, I\left(T_{3}\right)=B, I\left(T_{4}\right)=0
$$

Substituting $R(t)=D$ and $K(t)=\lambda_{0} R(t)$ in the equations (1)(4) and solving then using the boundary conditions (5), we get the following solutions:

$$
\begin{aligned}
& I(t)=-D t, \quad 0 \leq t \leq T_{1} \\
& I(t)=\left(\lambda_{0}-1\right) D\left(t-T_{2}\right), \quad T_{1} \leq t \leq T_{2} \\
& I(t)=\left(\lambda_{0}-1\right) D\left(t-T_{2}\right), \quad T_{2} \leq t \leq T_{3} \\
& I(t)=D\left(T_{4}-t\right), \quad T_{3} \leq t \leq T_{4}
\end{aligned}
$$

Using the condition $\mathrm{I}(\mathrm{t})=-\mathrm{A}$ and $t=T_{1}$ in (6) and (7) and then equating the two values of $\mathrm{A}$, we get

$$
T_{1}=\left(\frac{\lambda_{0}-1}{\lambda_{0}}\right) T_{2}
$$

Again using $I(t)=B$ and $\quad t=T_{2}$ in (8) and (9) and then equating the two values of $B$, we get

$$
T_{3}=\frac{\left(\lambda_{0}-1\right) T_{2}+T_{4}}{\lambda_{0}}
$$

Now, we shall try to find the different costs involved in the system,

The total shortage cost in the system is

$$
S C=\left[\int_{0}^{T_{1}}-I(t) d t+\int_{T_{1}}^{T_{2}}-I(t) d t\right]=\frac{C_{2} D}{2}\left[T_{1}^{2}+\left(\lambda_{0}-1\right)\left(T_{1}-T_{2}\right)^{2}\right]
$$

The total inventory holding cost in the system is

$$
H C=\left[\int_{T_{2}}^{T_{3}} I(t) d t+\int_{T_{3}}^{T_{4}} I(t) d t\right]=\frac{C_{1} D}{2}\left[\left(\lambda_{0}-1\right)\left(T_{3}-T_{2}\right)^{2}+\left(T_{4}-T_{3}\right)^{2}\right]
$$

Hence total average cost in the system is,

$$
\begin{aligned}
& A C=\frac{\left(S C+H C+C_{3}\right)}{T_{4}} \\
& =\frac{C_{2} \frac{D}{2}\left[T_{1}^{2}+\left(\lambda_{0}-1\right)\left(T_{1}-T_{2}\right)^{2}\right]+C_{1} \frac{D}{2}\left[\left(\lambda_{0}-1\right)\left(T_{3}-T_{2}\right)^{2}+\left(T_{4}-T_{3}\right)^{2}\right]+C_{3}}{T_{4}}
\end{aligned}
$$

For finding optimal values of $T_{i}: \mathrm{i}=1,2,3,4$; we convert $T_{1}$ and $T_{3}$ in terms of $T_{2}$ and $T_{4}$

$$
=\frac{1}{T_{4}}\left[\frac{C_{2} D}{2}\left(1-\frac{1}{\lambda_{0}}\right) T_{2}^{2}+\frac{C_{1} D}{2}\left\{\frac{\left(\lambda_{0}-1\right)}{\lambda_{0}^{2}}\left(T_{4}^{2}-2 T_{2} T_{4}+\lambda_{0} T_{2}^{2}\right)\right\}+C_{3}\right]
$$

The optimal value of $\mathrm{T}_{2}$ and $\mathrm{T}_{4}$, is obtained by solving $\frac{\partial(A C)}{\partial T_{2}}=0$, and $\frac{\partial(A C)}{\partial T_{4}}=0$ we get,

$$
\begin{aligned}
& \lambda_{0}\left(C_{1}+C_{2}\right) T_{2}-C_{1} T_{4}=0 \\
& \left(\lambda_{0}-1\right)\left\{C_{1} D T_{4}^{2}-\left(C_{1}+C_{2}\right) D T_{2}^{2}\right\}-2 \lambda_{0} C_{3}=0 \\
& \text { Since, } \frac{\partial^{2}(A C)}{\partial T_{2}^{2}}>0 \text {, and } \frac{\partial^{2}(A C)}{\partial T_{4}^{2}}>0 \text {, and }\left(\frac{\partial^{2}(A C)}{\partial T_{2}^{2}}\right)\left(\frac{\partial^{2}(A C)}{\partial T_{4}^{2}}\right)-\left(\frac{\partial^{2}(A C)}{\partial T_{2} \partial T_{4}}\right)^{2}>0
\end{aligned}
$$

This shows that average cost (AC) will be minimum.

Solving equations (16) and (17), we get different value of $\mathrm{T}_{2}$ and $\mathrm{T}_{4}$ for changing different parameters.

\section{Numerical Example}

Let $\lambda_{0}=1.05, C_{1}=20, C_{2}=30, C_{3}=40, D=100$ in appropriate units from (16) and (17), we obtain the optimal values of $T_{2}$ and $T_{4}$. Putting the optimal value of $T_{2}$ and $T_{4}$ in equation (10) and (11), we obtain the optimal values of $T_{1}$ and $T_{3}$ respectively.

We get, $T_{1}=.02726, T_{2}=.5725, T_{3}=1.4576, T_{4}=1.5029$ and Total average cost ' $\mathrm{AC}$ ' $=\$ 602.37$.

\section{Sensitivity Analysis}

All the observations from table 1 to 4 can be sum up as follows:

(i) From table 1, it can be easily seen that increase in the value of parameter $C_{1}$ will results increase in $T_{1}, T_{2}$ but decrease in $T_{3}, T_{4}$ and increase in average cost. 


\begin{tabular}{|l|l|l|l|l|l|}
\hline $\mathrm{C}_{1}$ & $\mathrm{~T}_{1}$ & $\mathrm{~T}_{2}$ & $\mathrm{~T}_{3}$ & $\mathrm{~T}_{4}$ & $\mathrm{AC}$ (in dollars) \\
\hline 20 & 0.0272 & 0.5725 & 1.4576 & 1.5029 & 602.37 \\
\hline 25 & 0.0300 & 0.6320 & 1.4206 & 1.4601 & 623.60 \\
\hline 30 & 0.0325 & 0.6831 & 1.3987 & 1.4345 & 637.91 \\
\hline 35 & 0.0346 & 0.7274 & 1.3855 & 1.4184 & 648.29 \\
\hline 40 & 0.0364 & 0.7660 & 1.3771 & 1.4077 & 656.38 \\
\hline 45 & 0.0380 & 0.8000 & 1.3714 & 1.4000 & 662.54 \\
\hline 50 & 0.3949 & 0.8297 & 1.3671 & 1.3940 & 669.27 \\
\hline 55 & 0.0407 & 0.8559 & 1.3635 & 1.3889 & 672.58 \\
\hline 60 & 0.0418 & 0.8788 & 1.3601 & 1.3842 & 677.02 \\
\hline
\end{tabular}

Table 1: Variation of $C_{1}$ keeping other parameters same as mentioned in numerical example.

\begin{tabular}{|l|l|l|l|l|l|}
\hline $\mathrm{C}_{2}$ & $\mathrm{~T}_{1}$ & $\mathrm{~T}_{2}$ & $\mathrm{~T}_{3}$ & $\mathrm{~T}_{4}$ & $\mathrm{AC}$ (in dollars) \\
\hline 30 & 0.0272 & 0.5725 & 1.4576 & 1.5029 & 602.37 \\
\hline 35 & 0.0235 & 0.4941 & 1.3822 & 1.4267 & 632.33 \\
\hline 40 & 0.0206 & 0.4344 & 1.3240 & 1.3685 & 657.51 \\
\hline 45 & 0.0184 & 0.3876 & 1.2782 & 1.3227 & 678.82 \\
\hline 50 & 0.0166 & 0.3498 & 1.2411 & 1.2857 & 697.25 \\
\hline 55 & 0.0151 & 0.3187 & 1.2106 & 1.2552 & 713.24 \\
\hline 60 & 0.0139 & 0.2927 & 1.1850 & 1.2296 & 727.20 \\
\hline 65 & 0.0128 & 0.2706 & 1.1632 & 1.2078 & 739.52 \\
\hline 70 & 0.0122 & 0.2516 & 1.1447 & 1.1891 & 750.55 \\
\hline 80 & 0.0105 & 0.2206 & 1.1138 & 1.1585 & 769.28 \\
\hline 90 & 0.0093 & 0.1964 & 1.0899 & 1.1345 & 784.56 \\
\hline 100 & 0.0084 & 0.1770 & 1.0706 & 1.1153 & 797.36 \\
\hline
\end{tabular}

Table 2: Variation of keeping other parameters same as mentioned in numerical examples.

\begin{tabular}{|l|l|l|l|l|l|}
\hline $\mathrm{C}_{3}$ & $\mathrm{~T}_{1}$ & $\mathrm{~T}_{2}$ & $\mathrm{~T}_{3}$ & $\mathrm{~T}_{4}$ & AC(in dollars) \\
\hline 40 & 0.0272 & 0.5725 & 1.4576 & 1.5029 & 602.37 \\
\hline 50 & 0.0304 & 0.6401 & 1.6300 & 1.6803 & 673.44 \\
\hline 60 & 0.0333 & 0.7012 & 1.7863 & 1.8407 & 737.73 \\
\hline 70 & 0.0360 & 0.7574 & 1.9295 & 1.9881 & 796.76 \\
\hline 80 & 0.0385 & 0.8096 & 2.0627 & 2.1254 & 851.90 \\
\hline 90 & 0.0408 & 0.8588 & 2.1879 & 2.2543 & 903.46 \\
\hline 100 & 0.0430 & 0.9052 & 2.3062 & 2.3763 & 952.43 \\
\hline 120 & 0.0472 & 0.9916 & 2.5532 & 2.6031 & 1043.33 \\
\hline 140 & 0.0509 & 1.0711 & 2.7376 & 2.8117 & 1126.90 \\
\hline 160 & 0.0545 & 1.1450 & 2.9172 & 3.0058 & 1204.74 \\
\hline 180 & 0.0578 & 1.2145 & 3.0941 & 3.1881 & 1277.75 \\
\hline 200 & 0.0609 & 1.2802 & 3.2615 & 3.3606 & 1346.89 \\
\hline
\end{tabular}

Table 3: Variation of keeping other parameters same as mentioned in numerical example.

(ii) From table 2, increase in the value of parameter $C_{2}$ will results in decrease in $T_{1}, T_{2}, T_{3}$ and $T_{4}$ but increase in average cost.

(iii) From table 3 , increase in the value $C_{3}$ of will results in increase in $T_{1}, T_{2}, T_{3}, T_{4}$ and average cost AC.

(iv) From table 4 , increase in the value $\lambda_{0}$ of will results in decrease in $T_{1}, T_{2}, T_{3}, T_{4}$ and average cost AC.

\section{Conclusion}

The model developed in this paper assumed that demand rate of a product is constant, shortages are allowed and replenishment rate is infinite, production rate is greater than demand rate and proportional to the demand rate. The effect of changing parameters is quite sensitive and makes significant difference to the changes. Numerical example is

\begin{tabular}{|l|l|l|l|l|l|}
\hline$\lambda_{0}$ & $\mathrm{~T}_{1}$ & $\mathrm{~T}_{2}$ & $\mathrm{~T}_{3}$ & $\mathrm{~T}_{4}$ & AC(in dollars) \\
\hline 1.1 & 0.0186 & 0.3912 & 1.6930 & 1.0758 & 476.74 \\
\hline 1.2 & 0.0124 & 0.2618 & 0.7606 & 0.7855 & 407.07 \\
\hline 1.3 & 0.0097 & 0.2049 & 0.6442 & 0.6662 & 387.47 \\
\hline 1.4 & 0.0081 & 0.1716 & 0.5804 & 0.6008 & 381.45 \\
\hline 1.5 & 0.0071 & 0.1494 & 0.5407 & 0.5603 & 380.87 \\
\hline
\end{tabular}

Table 4: Variation of Keeping other parameters same as mentioned in numerical example.

given to illustrate the model. Sensitivity analysis has been also given for changing the various parameters.

This model can be extended for several ways. For instance, we may extend the model for time-dependent demand rate. We could also generalised the model for cash discount, inflation etc

\section{References}

1. Goyal SK (1985) Economic order quantity under conditions of permissible delay in payments. J Oper Res Soc 36: 335-338.

2. Chung KJ, Goyal SK, Huang YF (2005) The optimal inventory policies under permissible delay in payments depending on the ordering quantity. Int $\mathrm{J}$ Prod Econ 95: 203-213.

3. Mahata GC, Mahata P (2009) Optimal Retailer's Ordering Policies in the EOQ Model for deteriorating items under Trade credit financing in supply chain. International Journal of Mathematical, Physical and Engineering Sciences 3 . 1-7.

4. Huang YF (2003) Optimal retailer's ordering policies in the EOQ model under trade order financing. J Oper Res Soc 54: 1011-1015.

5. Tripathi RP (2011) EOQ model with time-dependent demand rate and time dependent holding cost function. International Journal of Operational Research and Information Systems 2: 79-92.

6. Tripathi RP, Misra SS (2012) An Optimal Inventory Policy for Items having constant demand and constant deterioration rate with trade credit. International Journal of Information System and Supply Chain Management 5: 89-95.

7. Tripathi RP, Kumar M (2011) Credit financing in economic ordering policies of time-dependent deteriorating items. International Journal of Business, Management and Social Sciences 2: 75-84.

8. Uthaya Kumar R, Geetha KV (2009) A replenishment policy for noninstantaneous deteriorating inventory system with partial backlogging. Tamsu Oxford Journal of Mathematical Sciences 25: 313-332.

9. Tripathi RP, Mishra SS (2011) An inventory model with shortages, time dependent demand rate and quantity dependent permissible delay in payment.

10. Patra SK, Lenka TK, Ratha PC (2010) An order level EOQ model for deteriorating items in a single warehouse system with price dependent demand in non-linear (quadratic) form. International Journal of Computational and Applied Mathematics 5: 277-288.

11. Singh TJ, Singh SR, Dutt R (2009) An EOQ model for permissible items with power demand and partial backlogging. International Journal of Operations and Quality Management 15: 65-72.

12. Park KS (1982) Inventory models with partial backorders. International Journal of system science 13: 1313-1317.

13. Hollier RH, Mark KL (1983) Inventory replenishment policies for deteriorating items in a declining market. Int J Prod Res 21.

14. Wee HM (1995) Joint pricing and replenishment policy for deteriorating inventory with declining market. Int J Prod Econ 40: 163-171.

15. Abad PL (1996) Optimal Pricing and Lot-Sizing under Conditions of Perishability and Partial Backordering. Management Science 42: 1093-1104.

16. Chang HJ, Dye CY (1999) An EOQ model for deteriorating items with time varying demand and partial backlogging. J Oper Res Soc 50: 1176-1182.

17. Wang SP (2002) An inventory replenishment policy for deteriorating items with shortages and partial backlogging. Computers and Operational Research 29: 2043-2051. 
Citation: Tripathi RP, Sang N (2012) EOQ Model for Constant Demand Rate with Completely Backlogged and Shortages. J Applied Computat Mathemat 1:121. doi:10.4172/2168-9679.1000121

Page 4 of 4

18. Teng JT, Yang HL (2004) Deterministic economic order quantity models with partial backlogging when demand and cost are fluctuating with time. J Oper Res Soc 55: 495-503.

19. Yang HL (2005) A comparison among various partial backlogging inventory lotsize models for deteriorating items on the bases of maximum profit. Int $\mathrm{J}$ Prod Econ 96: 119-128.
20. Wu KS, Ouang LY, Yang CT (2006) An optimal replenishment policy for noninstantaneous deteriorating items with stock-dependent demand and partial backlogging. Int J Prod Econ 101: 369-384.

21. Dye CY, Ouang LY, Hsieh TP (2007) Deterministic inventory model for deteriorating items with capacity constraint and time-proportional backlogging rate. European Journal of Operational Research 178: 789-807. 